\title{
КОЛИЧЕСТВЕННЫЕ ПОКАЗАТЕЛИ ДИФФЕРЕНЦИРОВАННЫХ ДВИЖЕНИЙ МОРФОТЕКТОНИЧЕСКИХ БЛОКОВ НА ПОБЕРЕЖЬЕ КАНДАЛАКШСКОГО ЗАЛИВА БЕЛОГО МОРЯ
}

\section{Колька В.В., Корсакова О.П., Толстоброва А.Н., Толстобров Д.С., Вашков А.А.}

Геологический институт КНЦ РАН, Anamumbl, kolka@geoksc.apatity.ru

Современная тектоника побережья Кандалакшского залива Белого моря связана, во-первых, с гляциоизостатическим поднятием земной коры, вызванным экзогенными факторами, во-вторых, с блоковыми перемещениями по разломам, которые спровоцированы эндогенной активностью Онежско-Кандалакшского рифта, в-третьих, с унаследованным от докембрия общим поднятием Фенноскандинавского кристаллического щита.

Северо-восточное побережье залива (Кандалакшский берег) в основном приурочено к Кандалакшско-Колвицкому массиву Лапландско-Колвицкого гранулитового пояса, а юго-западное (Карельский берег) - к Беломорскому поясу. Обе отмеченные структуры входят в ЛапландскоБеломорский гранулито-гнейсовый подвижный пояс палеопротерозойской консолидации, вдоль оси которого в среднем-позднем рифее образовался Онежско-Кандалакшский палеорифт. В структурном плане к нему тяготеет акватория залива. В соответствии с классической схемой сегментации континентальных рифтов [5] он представлен здесь двумя современными полуграбенами с переменной полярностью. При этом Колвицкий асимметричный грабен (полуграбен) характеризуется северо-восточным крутым бортом с видимой амплитудой сброса более 50 м и правосторонним смещением блоков кристаллических фундамента вдоль разломов северо-западного и субмеридионального простирания. Есть мнение, что Колвицкий грабен сформировался в поздне-послеледниковое время [1], хотя конкретные свидетельства этому пока не приводятся. Кандалакшский асимметрич-

Исходны е материалы

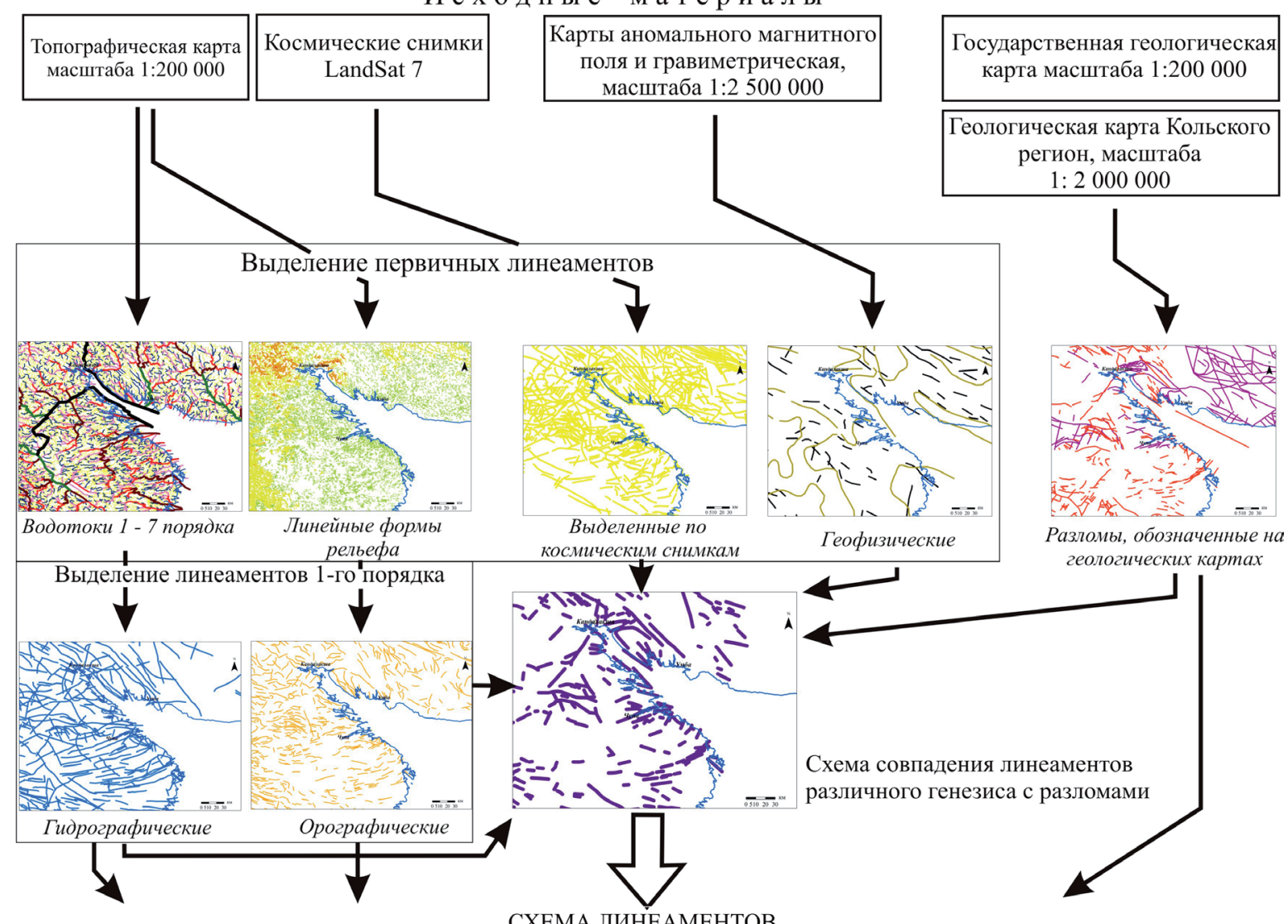

Рис.1. Схема проведения линеаментного анализа. 


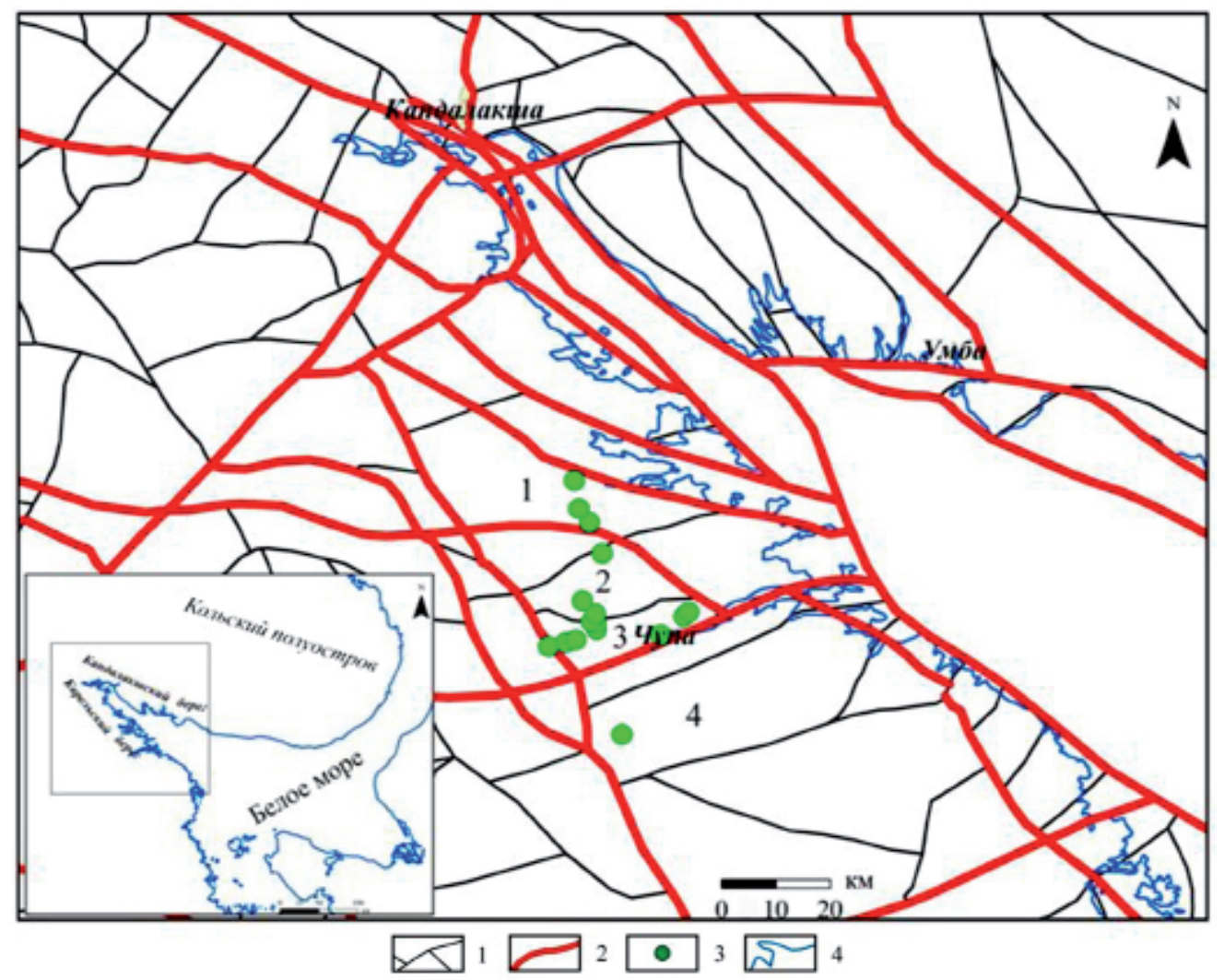

Рис. 2. Схема линеаментов, разделяющих морфотектонические блоки на побережье Кандалакшского залива и прилегающей территории.

Условные знаки: 1 -границы блоков по результатам линеаментного анализа, 2 - границы блоков подтвержденные геологическими данными, 3 - изученные озерные котловины, 4 - береговая линия. Цифрами обозначены блоки, исследованные в районе пос. Чупа: 1 - Тэдинский; 2 - Верхне-Пуломский; 3 - Чупинский 4 - Лоухский.

ный грабен (полуграбен), наследующий древнюю рифейскую впадину и соответствующий наиболее глубоководной части Белого моря, имеет приподнятое юго-западное крыло с амплитудой сброса более 200 м. Косая перемычка между этими двумя сегментами, т.е. зона переноса напряжений растяжения с одного отрезка рифта на другой, соотносится с грядой архипелага Средние Луды. Пологий северо-восточный борт Кандалакшского полуграбена осложнен сбросами и взбросо-надвигами, главный из которых представлен Оленицким валом [1].

В работах, посвященных позднеплейстоцен-голоценовой тектонике беломорского побережья, часто встречаются упоминания о «дифференцированных движениях морфотектонических блоков», которые подразумевают под собой вертикальное перемещение морфотектонических блоков, ограниченных тектоническими разломами. Эти блоки могут быть как планетарного размера, например, весь Кольский полуостров [4], так и размером в несколько квадратных километра [2]. Окончательно также не определено, что значит «дифференцированные» движения блоков. Это могут быть и движения разных блоков в разных направлениях, и однонаправленное поднятие блоков, но с разными скоростями. Пока что нет ответа и на вопрос о скоростях этих движений. Задача этой работы состояла в том, чтобы попытаться ответить на некоторые из этих вопросов. Для этого был выбран район на карельском побережье Кандалакшского залива Белого моря в районе пос. Чупа, который находится на границе Кандалакшского и Колвицкого полуграбенов (рис. 1).

\section{Методика проведенных исследований}

Для определения наличия или отсутствия дифференцированных вертикальных движений соседних блоков авторами был проведен линеаментный анализ территории (рис. 1) и выделены блоки земной коры в вершине Кандалакшского залива (рис. 2). В районе пос. Чупа в пределах нескольких 
выделенных блоков были выбраны озерные депрессии с одинаковыми высотными отметками порогов стока из них (рис. 2).

Далее применялся метод изолированных бассейнов [3]. В каждом озере отбирался керн донных осадков. Непосредственно в поле выделялись различные фации литологической последовательности (морские, переходные, озерные). Фациальная принадлежность к различным условиям седиментации уточнялась диатомовым анализом. Из переходных интервалов отбирались пробы для радиоуглеродного датирования. Полученные датировки из озер с одинаковыми высотными отметками, расположенных в разных блоках, сравнивались для того, чтобы для каждой котловины установить время смены морской седиментации на озерную. Если в разных блоках время смены условий седиментации примерно одинаковое, то вертикальные движения по блокам отсутствуют, и в регионе имеет место гляциоизостатическое куполообразное воздымание территории, ранее покрывавшейся ледником. Если же будут получены значительные возрастные различия для смены условий седиментации, то можно говорить о дифференцированных вертикальных движениях блоков.

\section{Полученные результаты}

Здесь приводятся предварительные результаты. В Лоухском блоке (рис. 1, 3) было изучено озеро с отметками порога стока 80 м н.у.м. Озеро с таким же отметками изучено и в Чупинском блоке. Установлено, что в озерной депрессии в Чупинском блоке смена морских условий седиментации на озерные произошла примерно на 1500 календарных лет раньше, чем в Лоухском блоке. В озерах с высотными отметками 69 м н.у.м. из Верхне-Пуломского блока и Чупинского блока (рис. 1) такая разница составила примерно 2500 календарных лет (кал. лет).

В озерах, расположенных на более низких отметках (52,0, 40,0, 33,0 м н.у.м.), в исследованных блоках разница составляла примерно 500 календарных лет.

Установлено, что скорость поднятия блоков в разные временные интервалы изменялась по-разному (рис. 4). В Чупинском блоке максимальная скорость перемещения его поверхности ( 10 см/год) отмечена во временном интервала 11.1-11.4 тыс. кал. лет. Во временном интервале 9.9-10.2 тыс. кал. лет она резко уменьшается до 1 см/год, а в середине голоцена падает незначительно. Здесь установлена и самая высокую скорость перемещения для всех изученных блоков во временном интервала 11.1-11.4 тыс. кал. лет.

Верхне-Пуломский блок демонстрирует уменьшение скорости перемещения от позднеледниковья до раннего голоцена и последующее ее увеличение в середине голоцена (рис. 4). Этот блок

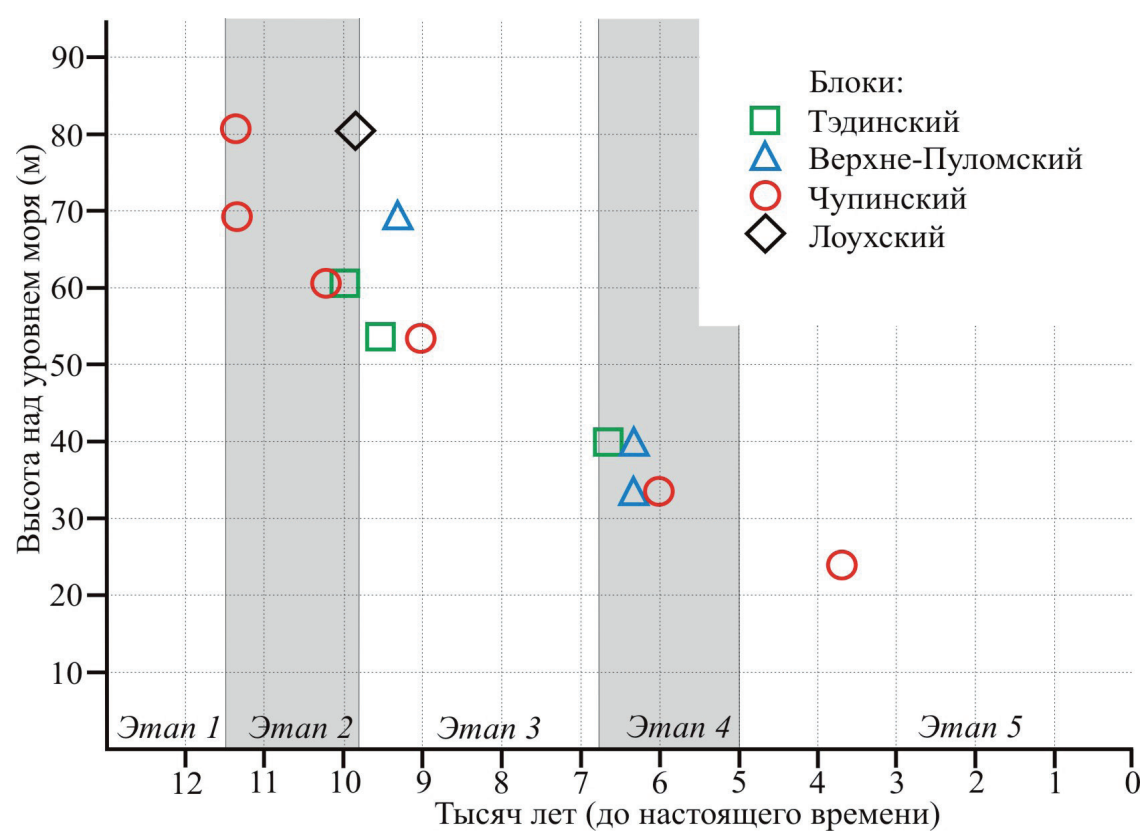

Рис. 3. Графическая корреляция полученных данных. 


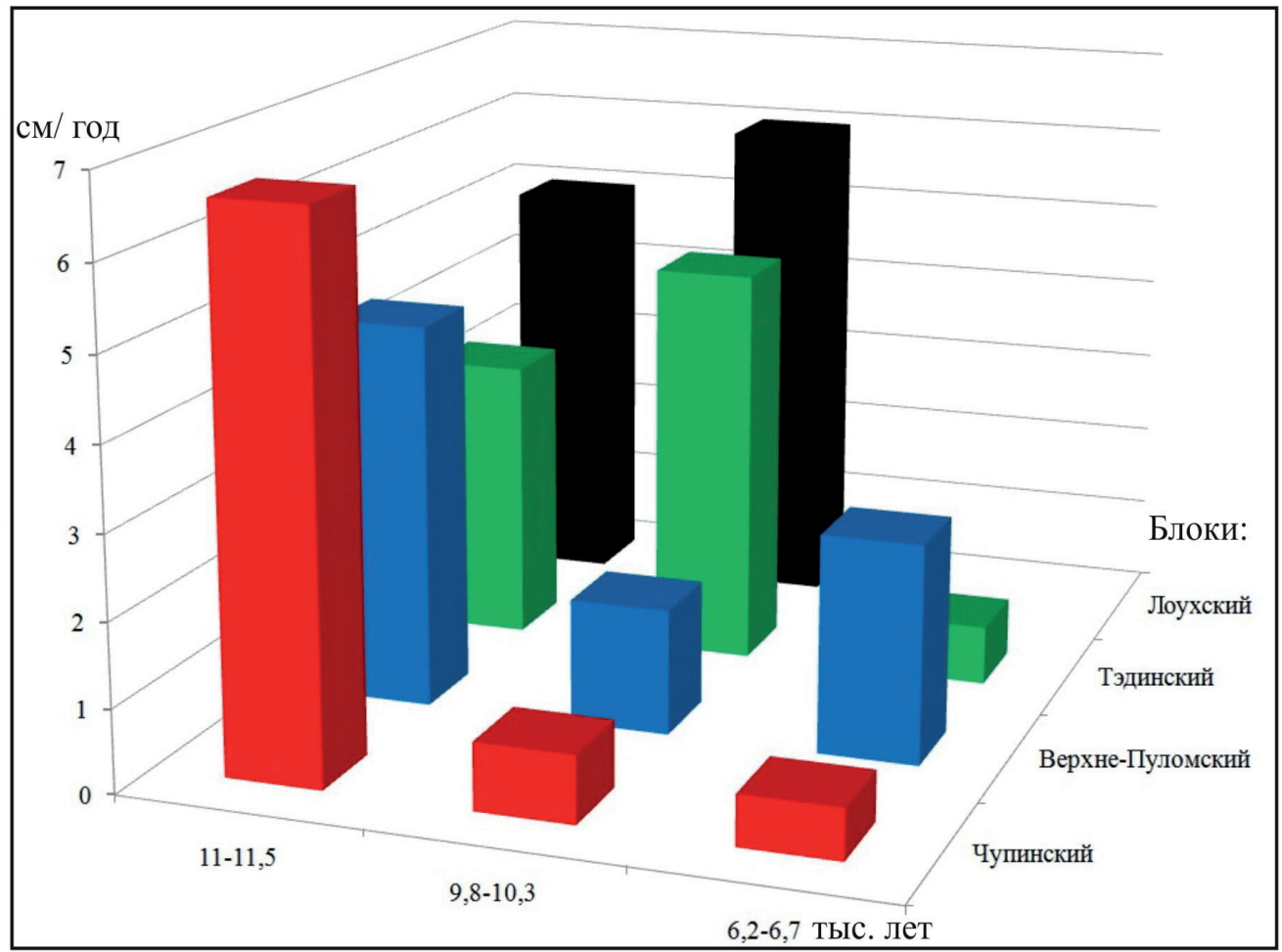

Рис. 4. Скорость поднятия блоков в различные периоды голоцена.

среди трех изученных блоков перемещался с наибольшей скоростью в среднем голоцене (временной интервал 6.3-6.6 тыс. кал. лет).

Тединский блок наибольшие скорости перемещения (до 8 см/год) демонстрировал в раннем голоцене (9.9-10.2 тыс. кал. лет), а в позднеледниковое время они были значительно ниже ( $\sim 5$ см/год) (рис. 4). В позднем голоцене (6.3-6.6 тыс. кал. лет) в этом блоке скорости перемещения снизились значительно - до 0.5 см/год. С наибольшей скоростью относительно других блоков Тединский блок перемещался в раннем голоцене 9.9-10.2 тыс. кал. лет.

Лоухский блок в позднеледниковье и в раннем голоцене перемещался примерно с одинаковой скоростью - 5 см/год. Данных о перемещении его в другое время пока не получено.

Исходя из полученных результатов, можно сделать вывод о проявлении дифференцированных вертикальных движениях на побережье Кандалакшского залива и количественно оценить скорости этих перемещений. Для исследованного района такие результаты получены впервые.

Работа выполнялась при поддержке гранта РФФИ № 16-05-00311-а и в рамках темы НИР № 0231-2015-0010.

\section{Литература}

1. Балуев А.С., Журавлев В.А., Терехин Е.Н., Пржиялговский Е.С. Тектоника Белого моря и прилегающих территорий (Объяснительная записка к «Тектонической карте Белого моря и прилегающих территорий» масштаба 1:15000000). М.: ГЕОС, 2012. 104 с.

2. Баранская А.В. Роль новейших вертикальных тектонических движений в формировании рельефа побережий Российской Арктики. Автореферат дис. ... канд. географ. наук. СПб., 2015. 26 с.

3. Колька В.В., Корсакова О.П., Шелехова Т.С., Толстоброва А.Н. Восстановление относительного положения уровня Белого моря в позднеледниковье и голоцене по данным литологического, диатомового анализов и радиоуглеродного датирования донных отложений малых озер в районе Чупа (северная Карелия) // Вестник МГТУ, 2015. Т. 18. № 2. С. 255-268.

4. Кошечкин Б.И. Голоценовая тектоника восточной части Балтийского щита. Л.: Наука, 1979. 160с.

5. Bosworth W. Geometry of propagation continental rifts // Nature, 1985. V. 316. № 5. P. 625-627. 